Article

\title{
Solution of Multi-Crew Depots Railway Crew Scheduling Problems: The Chinese High-Speed Railway Case
}

\author{
Chunxiao Zhao, Junhua Chen *, Xingchen Zhang and Zanyang Cui \\ School of Traffic and Transportation, Beijing Jiaotong University, Beijing 100044, China; \\ 18114057@bjtu.edu.cn (C.Z.); xczhang@bjtu.edu.cn (X.Z.); 19114031@bjtu.edu.cn (Z.C.) \\ * Correspondence: cjh@bjtu.edu.cn
}

check for updates

Citation: Zhao, C.; Chen, J.; Zhang, X.; Cui, Z. Solution of Multi-Crew Depots Railway Crew Scheduling Problems: The Chinese High-Speed Railway Case. Sustainability 2022, 14, 491. https://doi.org/10.3390/ su14010491

Academic Editor: Marco Guerrieri

Received: 28 November 2021

Accepted: 28 December 2021

Published: 3 January 2022

Publisher's Note: MDPI stays neutral with regard to jurisdictional claims in published maps and institutional affiliations.

Copyright: (C) 2022 by the authors. Licensee MDPI, Basel, Switzerland. This article is an open access article distributed under the terms and conditions of the Creative Commons Attribution (CC BY) license (https:// creativecommons.org/licenses/by/ $4.0 /)$.

\begin{abstract}
This paper presents a novel mathematical formulation in crew scheduling, considering real challenges most railway companies face such as roundtrip policy for crew members joining from different crew depots and stricter working time standards under a sustainable development strategy. In China, the crew scheduling is manually compiled by railway companies respectively, and the plan quality varies from person to person. An improved genetic algorithm is proposed to solve this large-scale combinatorial optimization problem. It repairs the infeasible gene fragments to optimize the search scope of the solution space and enhance the efficiency of GA. To investigate the algorithm's efficiency, a real case study was employed. Results show that the proposed model and algorithm lead to considerable improvement compared to the original planning: (i) Compared with the classical metaheuristic algorithms (GA, PSO, TS), the improved genetic algorithm can reduce the objective value by $4.47 \%$; and (ii) the optimized crew scheduling plan reduces three crew units and increases the average utilization of crew unit working time by $6.20 \%$ compared with the original plan.
\end{abstract}

Keywords: high-speed railway; crew scheduling; multi-crew depots; genetic algorithm

\section{Introduction}

The sustainable development of transportation is a global focus. Railway transportation, especially high-speed railway, not only has fast travel speed and large capacity, but also has low energy consumption, so it has always been the focus of development in various countries such as the ICE in Germany, TGV in France, Shinkansen in Japan, and so on. Scientific studies show that railway transportation can reduce 20 million tons of carbon dioxide emissions under the same conditions as roads. For railway, achieving sustainable development not only requires updated transportation equipment to improve energy efficiency, but also needs to improve the quality of the transportation organization to ensure that transportation resources can be effectively used. Since infrastructure costs cannot be influenced substantially, personnel costs become a critical factor after rolling stock and energy. It is generally considered that the crew planning problem is an operational issue that is the task of building a work schedule for crew members to operate a planned timetable. Hence, the interest in using advanced optimization techniques for the complex crew scheduling task has arisen.

The remainder of this paper is organized as follows. A brief review of the relevant literature is presented in Section 2. Problem description and base mathematical model are given in Section 3. Section 4 proposes the solution algorithm for the crew scheduling problem. In Section 5, a real case study is presented, and the proposed solution algorithm is employed. Discussions are also given in the same section. Section 6 provides a conclusion and recommendations for future studies.

\section{Literature Review}

Crew planning problems in transportation originate in the airline and bus industries. Since the 1950s, foreign scholars, especially European scholars, began to study the Crew 
Planning Problem (CPP) [1] and gained greater momentum with the advances in computational power in 1980s [2,3]. Early studies were mainly concentrated on airlines [4,5], and followed by urban public transportation [6-8]. So far, many achievements have been made in the field of crew planning problems. Compared with other fields, the aviation field, which started earlier, has the most in-depth research and achieved fruitful results [9-14]. The research on the railway crew planning problem started relatively late. In the 1990s, the railway industry came to the fore in crew scheduling research activities. Several research groups from different countries contributed to the progress $[7,15,16]$. In previous studies, most scholars decomposed the crew planning problem into two steps: the crew scheduling problem (CSP) and the crew rostering problem (CRP). The first forms anonymous duties covering all the trips(tasks) for a defined period of time. Each duty represents a sequence of tasks and has to satisfy a large set of constraints. Next, the duties are combined to weekly, in some cases monthly, sequences that are subsequently assigned to individual crew members [17]. Feasible duty sequences typically follow rational/national/international legal and sustainable guidelines. Some studies have focused on the two sub-problems separately [18-20], and others have integrated the two steps into a unified optimization model for consideration [21-23]. Moreover, research on integrated planning came to the fore in the last year. A generic operational planning process [24] in railway transportation is illustrated in Figure 1. In most cases, they explore the integration of line planning and timetabling or timetabling and rolling stock scheduling $[25,26]$. The integration of crew scheduling with other planning tasks is mainly explored in freight transportation $[27,28]$ or crew rostering. Furthermore, some of the work was done in the context of crew re-scheduling for disruption management [29-31].

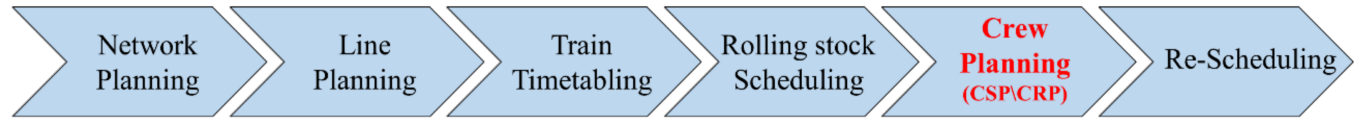

Figure 1. The operational planning process in passenger railway transportation.

Here, we focus on the first step of the crew planning problem on railways (crew scheduling problem). CSPs are typically formulated as mixed-integer problems. Most researchers have viewed it as a set covering problem or set partitioning problem $[19,32,33]$, which are both path-flow formulations. Few researchers have applied the arc-flow formulation of the multi-commodity flow problem, here referred to as network flow problem [22,34]. In order to achieve an optimal crew schedule, an appropriate evaluation criterion should be specified. In most cases, researchers have evaluated the efficiency of the CSP by total cost, the total number of duties, total idle time, or a combination of these $[35,36]$. Few researchers have not only considered pure monetary foal criteria, but also the quality of the solution in terms of robustness [30,31,37] and employee satisfaction [38]. CSP is governed by a great variety of legal rules and regulations by the public transport authorities, so different countries or operators have their own rules and restrictions. In general, constraints apply to different levels of a schedule: to the duty itself, to a depot, to the total schedule, or to specific types of crew members. Since CSPs are NP-hard optimization problems [39], integer programming methods are only applied to small or sparse problem instances. The computational complexity of CSP has led to extensive research in heuristics [40,41], column generation techniques [35,42,43], or meta-heuristics [44,45].

Traditionally, the type of crew members varies depending on the type of railway transportation, and it is common practice to schedule each type of crew (driver, conductor, catering staff, security guard) separately because of variations in the rules and restrictions [46,47]. The driver operates the train and the conductor is responsible for operational and safety activities [48]. In general, subways require only one, or even no train driver, and regional trains are often managed by a driver and conductors, though almost all researchers have taken the driver as a subject and ignored others, where in some cases, a distinction makes sense. For example, in China, the work schedules between the driver and conductor are different for the following reasons. (1) Compared with drivers, conductors are less 
affected by the radiation range of the crew depots, because drivers can only undertake tasks on fixed sections while the conductors' working routes are not fixed. In order to ensure driving safety, drivers can only work at a fixed section, while conductors can serve at any section according to the operation needs, which is more flexible. (2) Conductors can take on their duties for multiple trains, but for safety and other reasons, the drivers can only work on relatively fixed train types to guarantee that they are familiar with its performance. (3) The working time standard for train conductors is different from the drivers. Considering that fatigue driving affects safety, in general, the drivers must arrange a break for $4 \sim 5 \mathrm{~h}$ of continuous work while the train conductors usually continuously work for more than $10 \mathrm{~h}$. (4) In comparison, conductors are greatly influenced by train types. For high-speed railway, one set of drivers can complete operations of different train types, while the number of conductors should be allocated according to the specific conditions. (5). In general, the schedule for drivers and conductors are made by different institutions. This paper focused on the conductors, with the crew appearing below all referring to conductors.

The existing literature has fully explored the model formulation and algorithm solution on the crew scheduling problem, however, there is only few research that assesses the effects of specific measures on the employees' satisfaction and trade-offs between the conflicting objectives. The problem of how to attract talented professionals to rail organizations in an environment of increasing competition and choice is a real and ongoing challenge for the global rail industry. This topic has been on the workforce agenda for at least ten years and after a decade, is still widely debated. With plenty of discussion about attracting and retaining talent, skills shortages, mismatches of skills for new jobs, and jobs disappearing due to artificial intelligence and the increasing use of robots, few rail organizations acknowledge that the 21st century is a person-centered age. Many of the workforce issues that organizations cite about not finding the 'right' people or skills mix result from failure to communicate the right value proposition to the right people through the right channels [48,49]. Even without a strong work council, railway operators should aim for sustainable and fair crew schedules. Particularly in developed countries, labor markets become more competitive, so railway operators aim to make their jobs more appealing, which includes, besides payment and company culture, a satisfying and sustainable work schedule [17]. This paper plans to focus on the CSP against the background of the sustainable development of mankind. Although the main crew type discussed in this paper and the one investigated in the case studies is the conductor, the proposed framework is capable of dealing with the scheduling of the other types of crew members considering the cooperation of multi depots. The optimization of the crew scheduling problem from the perspective of sustainable development can increase the utilization of the crew members' working time and reduce the cost investment in crew members.

\section{Base Model Development}

\subsection{Problem Description and Assumption}

In this section, we developed a mathematical model for crew scheduling considering the cooperation of multiple crew depots. The main assumptions used for this model deals with crew scheduling, focusing on the situation, conditions, and limitations of the companies dealing with passenger trains. The crew depots (also: crew bases) are used in the crew scheduling process to subdivide train journeys into smaller units, called trips or pieces, following the terminology in rolling stock scheduling. Trips are the smallest amount of work defined by a fixed starting and ending time at each location and can be assigned to a crew member. Each crew member is assigned to a crew depot, which is often located at terminals or stations with a high frequency of train services [17]. Typically, there are multiple depots in railway networks. A trip in a scheduled timetable generally contains these properties: train id, origin station, departure time, destination station, arrival time, stops, and required number of crew units [20]. Here, we regarded the group of a conductor and five stewards as a crew unit, and the group serves a train with 8-carriages. In such 
trips, the origin and destination can belong to different companies and the required number of crew units are different. Although some limitations may exist in assigning crew units to the trips (e.g., the crew units and trips must belong to the same company or the crew units should have licenses for the train type), we assumed that all crew units are eligible to perform any trips. Furthermore, from the perspective of the sustainable development of mankind, we limited dead-heading and night residents to reduce the fatigue of the crew and improve their work efficiency.

The aim of this mathematical model was to find a set of feasible duties that covers all the trips regarding the existing limitations and conditions. A duty is a sequence of scheduled trips that is to be assigned to a crew unit. A feasible set of duties needs to meet all contractual and legal requirements based on each country's regulations. Most of the limitations observed in Chinese train companies form the constraints of the proposed model.

\subsection{Parameters, Decision Variables, and Notations}

The notations, input parameters, and variables for the optimization problems under consideration are listed as Table 1.

Table 1. Parameters, decision variables, and notations.

\begin{tabular}{|c|c|}
\hline Notations & Description \\
\hline \multicolumn{2}{|r|}{ Sets } \\
\hline$D$ & Set of crew depots, indexed by $d \in D$ \\
\hline $\operatorname{Tr}$ & Set of complete trips \\
\hline$K_{d}$ & Set of duties in crew depot $d$, indexed by $k \in K_{d}$ \\
\hline$N$ & Set of crew depots and complete trips, indexed by $i, j, \in N$ \\
\hline \multicolumn{2}{|r|}{ Parameters } \\
\hline$T D_{i}$ & Theat the origin \\
\hline$T A_{i}$ & Theat the destination \\
\hline$T S_{i}$ & The duration of the trip $i$ \\
\hline$\underline{t}$ & The minimum time needed for crew units to change the trip \\
\hline $\bar{L}$ & The maximum allowed working time for a crew unit \\
\hline$m_{i}$ & The required number of crew units of the trip $i$ \\
\hline$s_{i j}$ & $\begin{array}{c}\text { The value is equal to } 1 \text { if the destination of the trip } i \text { is the same as the origin } \\
\text { of trip } j, 0 \text { otherwise }\end{array}$ \\
\hline$c_{1}$ & The transit cost between trip $i$ and trip $j$ \\
\hline$c_{2}$ & The night resident cost \\
\hline$c_{3}$ & The duty fixed cost \\
\hline$M$ & An infinite number to ensure that the constraint is valid \\
\hline \multicolumn{2}{|r|}{ Variables } \\
\hline$x_{i j k}^{d}$ & $\begin{array}{l}\text { The binary variable, which is equal to } 1 \text { if the duty } k \text { in crew depot d services } \\
\text { trip } j \text { after trip } i, 0 \text { otherwise }\end{array}$ \\
\hline$t_{k}^{d}$ & Cumulative work time of duty $k$ in crew depot $d$ \\
\hline$t_{i k}^{d}$ & The starting time for duty $k$ in crew depot $d$ to service trip $i$ \\
\hline$y_{i k}^{d}$ & $\begin{array}{l}\text { The binary variable, which is equal to } 1 \text { if trip } i \text { is assigned to duty } k \text { in crew } \\
\text { depot } d\end{array}$ \\
\hline
\end{tabular}

\subsection{Mathematical Model}

$$
\begin{gathered}
\operatorname{Min} z=c_{1} \cdot \sum_{i \in T r} \sum_{j \in T r} \sum_{d \in D} \sum_{k \in K_{d}} x_{i j k}^{d}\left(T D_{j}-T A_{i}\right)+c_{2} \\
\cdot \sum_{d \in D} \sum_{k \in K_{d}}\left[\sum_{j \in T} x_{d j k}^{d} \cdot \sum_{d^{\prime} \in D \backslash\{d\}} \sum_{j \in T} x_{j d^{\prime} k}^{d^{\prime}}\right]+c_{3} \cdot \sum_{i \in D} \sum_{k \in K_{d}} \sum_{j \in T} x_{i j k}^{d} \\
\sum_{k \in K_{d}} \sum_{j \in T} x_{i j k}^{d} \leq K_{d}, \forall i \in D
\end{gathered}
$$




$$
\begin{gathered}
t_{k}^{d}=\sum_{i \in N} \sum_{j \in N \backslash\{i\}} x_{i j k}^{d}\left(T D_{j}-T A_{i}+T S_{i}\right), \forall d \in D, k \in K_{d} \\
t_{k}^{d} \leq L, \forall d \in D, k \in K_{d} \\
\sum_{d \in D} \sum_{k \in K_{d}} y_{i k}^{d}=m_{i}, \forall i \in T r \\
\sum_{i \in N \backslash\{j\}} \sum_{d \in D} \sum_{k \in K_{d}} x_{i j k}^{d}=y_{j k}^{d}, \forall j \in T r \\
\sum_{j \in N \backslash\{i\}} \sum_{d \in D} \sum_{k \in K_{d}} x_{i j k}^{d}=y_{i k}^{d}, \forall i \in T r \\
\sum_{j \in T r} x_{i j k}^{d} \leq 1, \forall i \in D, k \in K_{d} \\
\sum_{i \in D} \sum_{j \in T r} x_{j i k}^{d} \leq 1, \forall k \in K \\
t_{j k}^{d} \geq t_{i k}^{d}+T S_{i}+\underline{t}-M\left(1-x_{i j k}^{d}\right), \forall i, j \in T r, i \neq j, d \in D, k \in K_{d} \\
t_{j k}^{d} \leq T D_{i}, \forall d \in D, k \in K_{d}, i \in T r \\
x_{i j k}^{d} \leq y_{i k}^{d} \cdot s_{i j}, \forall i, j \in T r, i \neq j, d \in D, k \in K_{d} \\
x_{i j k}^{d} \leq y_{j k}^{d} \cdot s_{i j}, \forall i, j \in T r, i \neq j, d \in D, k \in K_{d} \\
x_{i, j, k}^{d} \geq y_{i k}^{d} \cdot s_{i j}+y_{j k}^{d} \cdot s_{i j}-1, \forall i, j \in T r, i \neq j, d \in D, k \in K_{d}
\end{gathered}
$$

The objective function (1) minimizes the total system cost including the transit cost between trips, night resident cost, and duty cost. Constraint (2) ensures that the number of duties starting from each crew depot will not deviate from the number of crew units available in the crew depot. Constraints (3) and (4) ensure that each duty's working time is less than the maximum allowed working time. Constraint (5) ensures that each trip must be assigned to the required number of duties. Constraints (6) and (7) ensure that each duty forms a closed tour. Each duty's origin and destination is guaranteed by Constraints (8) and (9). Constraints (10) and (11) ensure that the crew unit must make preparations before the specified departure time of the trip. The prevention of crew unit traveling as passengers between the trips is guaranteed by Constraints (12), (13), and (14).

\section{Solution Algorithm}

As described above, the proposed model contains a nonlinear item in the objective function. Although some optimization solvers can handle quadratic programming if the objective and constraints are positive semi-definite, the resultant model becomes significantly large, which makes it difficult to obtain the optimal solution in moderate and large scales of a problem using commercial solvers. Thus, we improved the genetic algorithm (GA) [50] to obtain a better solution. GA has a good global search ability and has been applied to solve various combinatorial optimization problems. However, crossover and mutation operations usually cause large infeasible solutions and reduce the viability of the population, leading to the advanced convergence of the algorithm. Inspired by the simulated evolutionary algorithm [51] and gene recombination [52], in this paper, the improved GA uses the elimination and regeneration method to repair the infeasible gene fragments to improve the quality of the population. The improved GA is shown in Figure 2. 


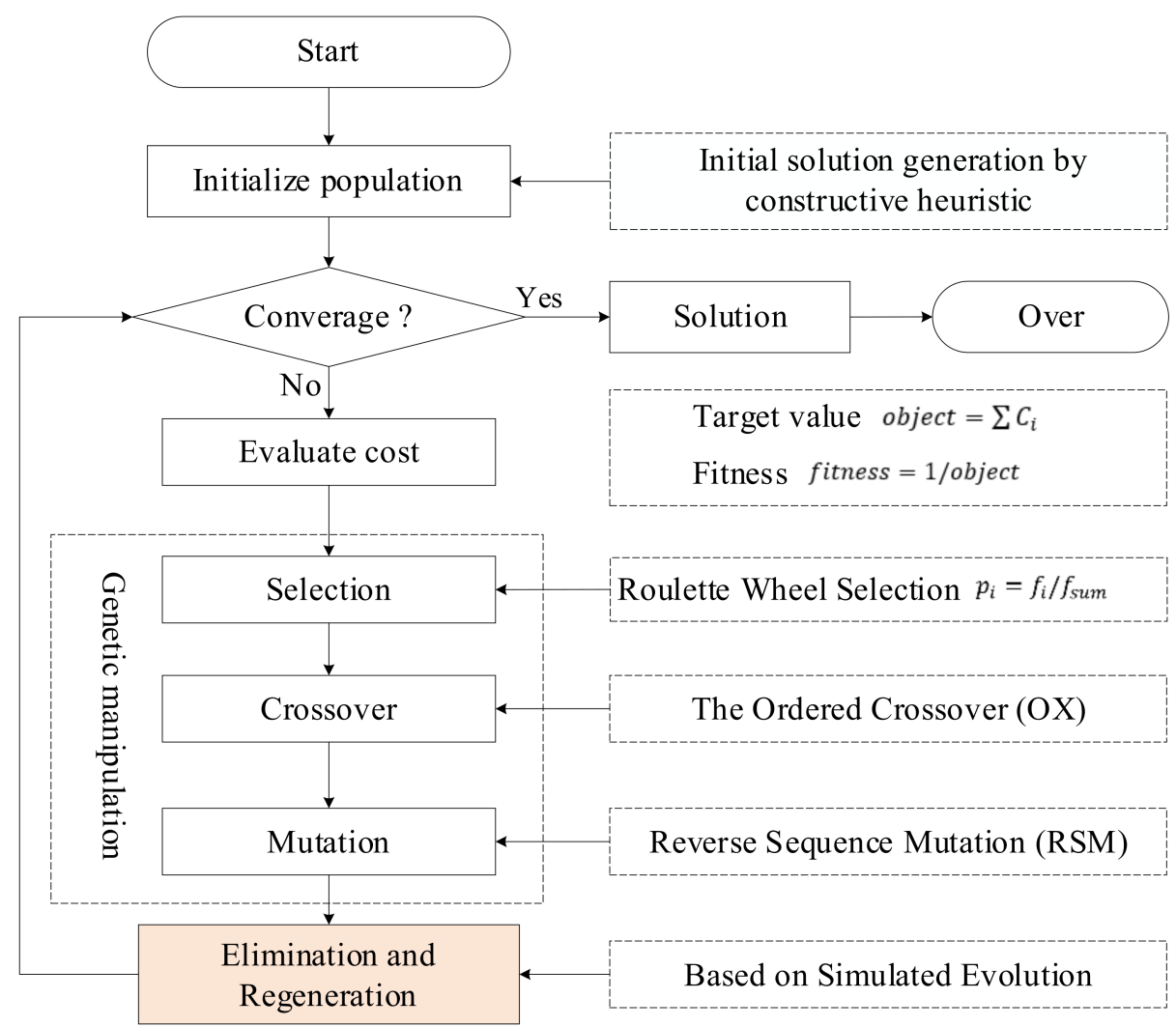

Figure 2. Flow diagram of the improved GA. The core is "Elimination and Regeneration", as shown in orange.

\subsection{Representation and Fitness Function}

As shown in Figure 3, TSP-like permutation chromosomes with trip delimiters were used. The segment between two adjacent crew points is the work content of a crew unit, for example, the crew unit of duty 1 departures from crew depot D1 and serves $\operatorname{Tr} 1, \operatorname{Tr} 2$, $\operatorname{Tr} 3$, and Tr4, and finally returns back to crew depot D1. A crew unit will not go back to their own crew depot after accomplishing the duty if the two adjacent crew points are not the same, for example, the crew unit of duty 2 has to reside in crew depot D2, which is not the same as the departure crew depot. We can easily convert the chromosome to duties as shown in Figure 4.

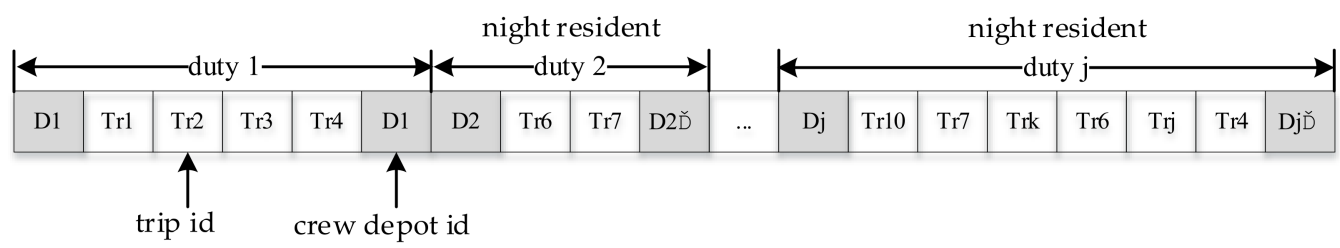

Figure 3. The representation of a solution. 


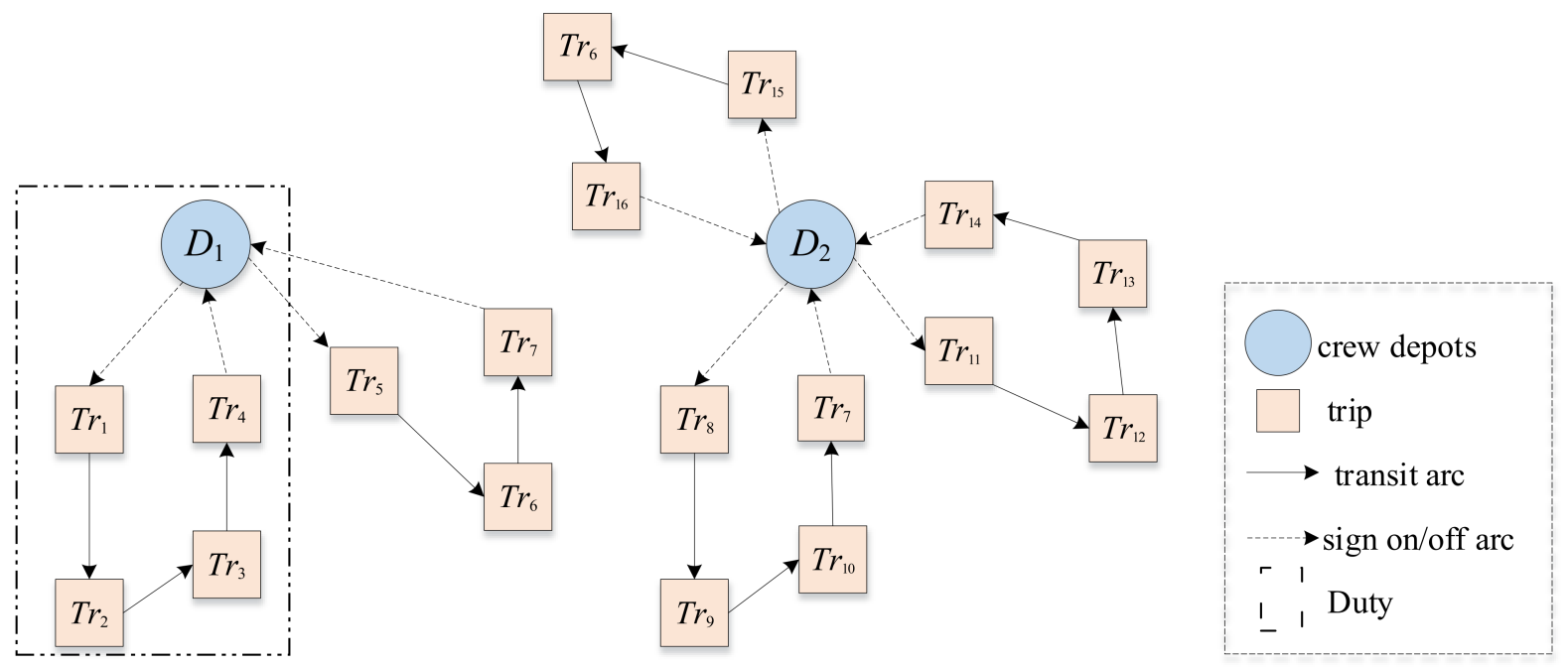

Figure 4. Illustration of duty.

Moreover, we can see that some trips appeared twice (i.e., $\operatorname{Tr} 6$ and $\operatorname{Tr} 7$ in Figure 4) if the train with 16-carriages needs two crew units. Note that Figure 4 is only a schematic diagram. The origin and destination of some duties may not be the same.

The fitness of a chromosome is directly related to the target of problem optimization. In this paper, fitness is defined as the reciprocal of the objective function (Equation (15)).

$$
f_{i}(n)=Z_{\text {max }}(n)-Z_{i}(n)
$$

where $f_{i}(n)$ is the fitness of chromosome $i$ at iteration $n ; Z_{i}(n)$ is the objective value chromosome $i$ at iteration $n$; and $Z_{\max }(n)$ is the max objective value of the population at iteration $n$.

\subsection{Initial Population}

The convergence of GA and the final solution quality are influenced by its initial population [53]. Therefore, it is essential to provide a good initial solution. The method of generating the initial solution is as follows:

Step 1. Initialization: $k=0, D=\varnothing$;

Step 2. $k=k+1$, randomly select a trip from $\operatorname{Tr}$ as the first trip of duty $k$, then mark it;

Step 3. For each trip in $T r$, if the trip is not marked but meets the Constraints (3)-(14), put it at the end of duty $k$, then mark it;

Step 4. If the departure crew depot and arrival crew depot of duty $k$ are the same, put duty $k$ in $D$, delete the marked trips from $T r$. If the departure crew depot and arrival crew depot of duty $k$ are not the same, and can back to the trip which can form a new closed duty $k^{\prime}$, put duty $k^{\prime}$ in $D$, then delete marked trips from $T r$. Otherwise, put duty $k$ in $D$, delete the marked trips from $T r$, and the duty $k$ will be punished.

Step 5. If $\operatorname{Tr}=\varnothing$, go to Step 6, otherwise, go to Step 2 .

Step 6. Repeat Steps (2)-(5) until obtaining the population of the given size.

\subsection{Selection}

Selection aims at selecting dominant descendants from a population. Various selection methods have been proposed such as wheel selection, stochastic tournament selection, stochastic universal selection, etc. In this paper, the roulette wheel selection was adopted.

\subsection{Crossover}

Crossover is one of the core parts of GA, aiming at obtaining better individuals from the previous generation population. Otman [54] studied the effects of different crossover operations on the genetic search process in TSP. The results show that the quality of the 
solution can be the best using the ordered crossover (OX) crossover operation. In this paper, the OX operation was adopted. The steps are as follows.

Step 1 . Randomly select two parents (i.e., $P_{1}=\{1,2,3,4,5,6,7,8\}, P_{2}=\{8,7,6,1,2,3,4,5\}$ ). Step 2 . Randomly determine two crossover points, Index $1=3$, Index $2=5$.

Step 3. Descendants inherit fathers' genes, $C_{1}=\{*, *, 3,4,5, *, *, *\}, C_{2}=\{*, *, 6,1,2, *, *, *\}$. Step 4. Sequentially insert the remaining genes of $P_{2}$ into $C_{1}$, sequentially insert the remaining genes of $P_{1}$ into $C_{2}, C_{1}=\{8,7,3,4,5,6,1,2\}, C_{2}=\{3,4,6,1,2,5,7,8\}$.

\subsection{Mutation}

After the crossover, the descendants are randomly adjusted by mutation. The mutation enlarges the diversity of solutions and searches space by small adjustments, which is helpful to find better solutions. This paper adopted the reverse sequence mutation (RSM) method. In RSM, two mutation points are randomly generated, then the genes are exchanged at two points.

\subsection{Elimination and Regeneration}

The crossover and mutation do not consider the connection time between two trips so that the descendants may violate the duty constraints. In this paper, the method of elimination and regeneration was used to solve this problem. There are two main stages (Figure 5): elimination and regeneration.

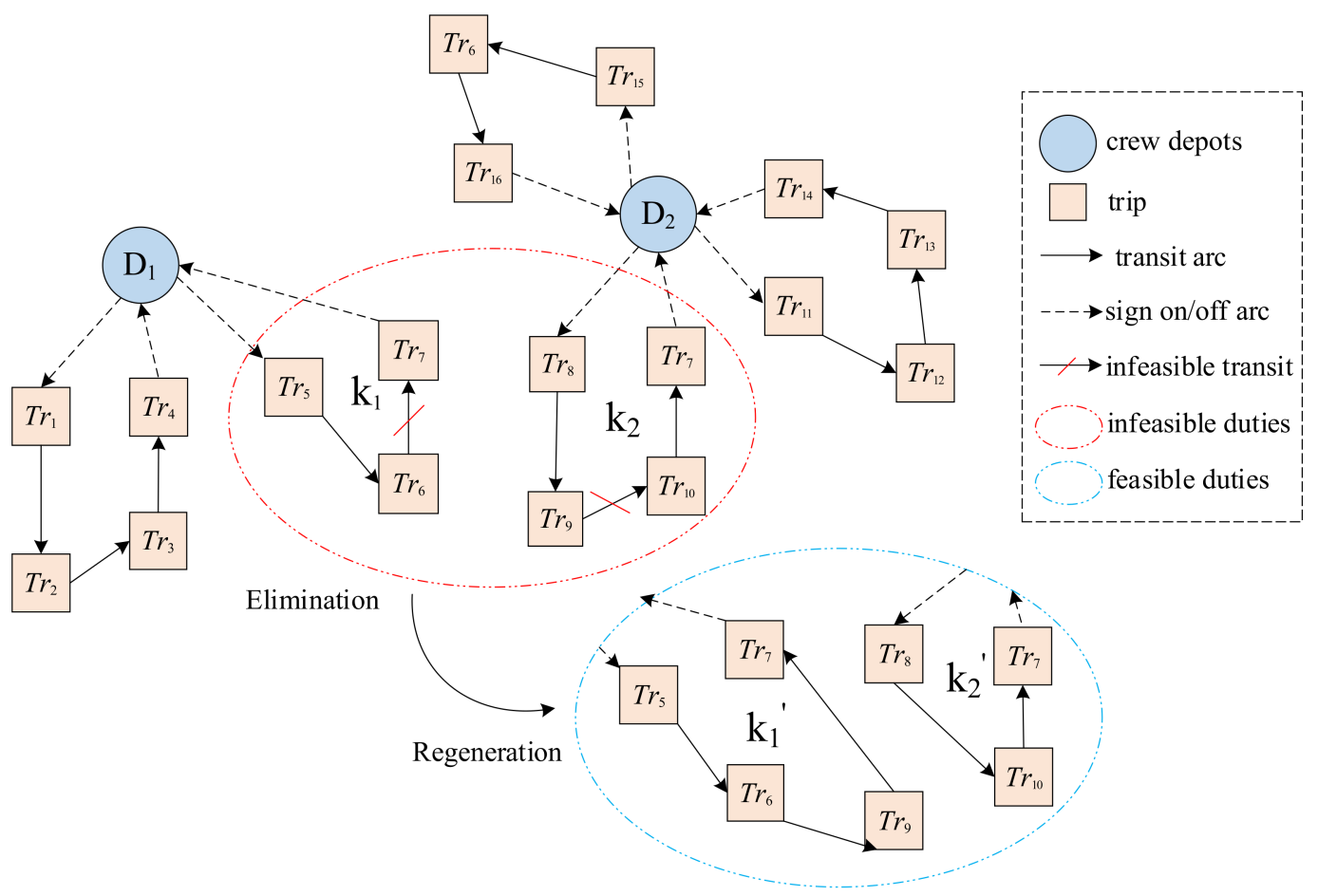

Figure 5. The processes of elimination and regeneration. The infeasible connection between trips will be broken, and then a new feasible connection will be formed according to the constraints.

(i) Elimination: First, judge individuals in the population, if one individual contains an infeasible chromosome fragment, delete this chromosome fragment and release the occupied resources. As shown in Figure 4, trip $\operatorname{Tr}_{6}$ and trip $\operatorname{Tr}_{7}$ are not satisfied with the constraints in the duty $k_{1}$ of crew depot $B_{1}$; trip $T r_{9}$ and trip $T r_{10}$ are not satisfied with the constraints in the duty $k_{2}$ of crew depot $B_{2}$. Therefore, duty $k_{1}$ and duty $k_{2}$ are eliminated, and their occupied trips are released.

(ii) Regeneration: New chromosome fragments are obtained by using the method above, and new individuals are formed by replacing the original unfeasible chromo- 
some fragments with new chromosome fragments. As shown in Figure 4, new duty $k_{1}^{\prime}=\left\{B_{1}, \operatorname{Tr}_{5}, \operatorname{Tr}_{6}, \operatorname{Tr}_{9}, \operatorname{Tr}_{7}, B_{1}\right\}$ and $k_{2}^{\prime}=\left\{B_{2}, \operatorname{Tr}_{8}, \operatorname{Tr}_{10}, \operatorname{Tr}_{7}, B_{2}\right\}$ are obtained, and new crew scheduling is formed by replacing the duty $k_{1}$ and duty $k_{2}$ with the duty $k_{1}^{\prime}$ and duty $k_{2}^{\prime}$.

\section{Case Study}

To validate the proposed model as well as analyze the efficiency of the proposed solution algorithm, the Wuhan-Guangzhou high-speed railway as a whole case study is provided in this section.

\subsection{Case Description}

The Wuhan-Guangzhou high-speed railway, which opened in 2009, is one of the busiest high-speed railway trunk lines in China. It has a total length of $1069 \mathrm{~km}$ and 16 stations (Figure 6). It operates more than 100 pairs of high-speed trains every day. This paper considered 75 high-speed trains on the Wuhan-Guangzhou high-speed railway and some cross-line trains (Wuhan-Shenzhen North) as input.

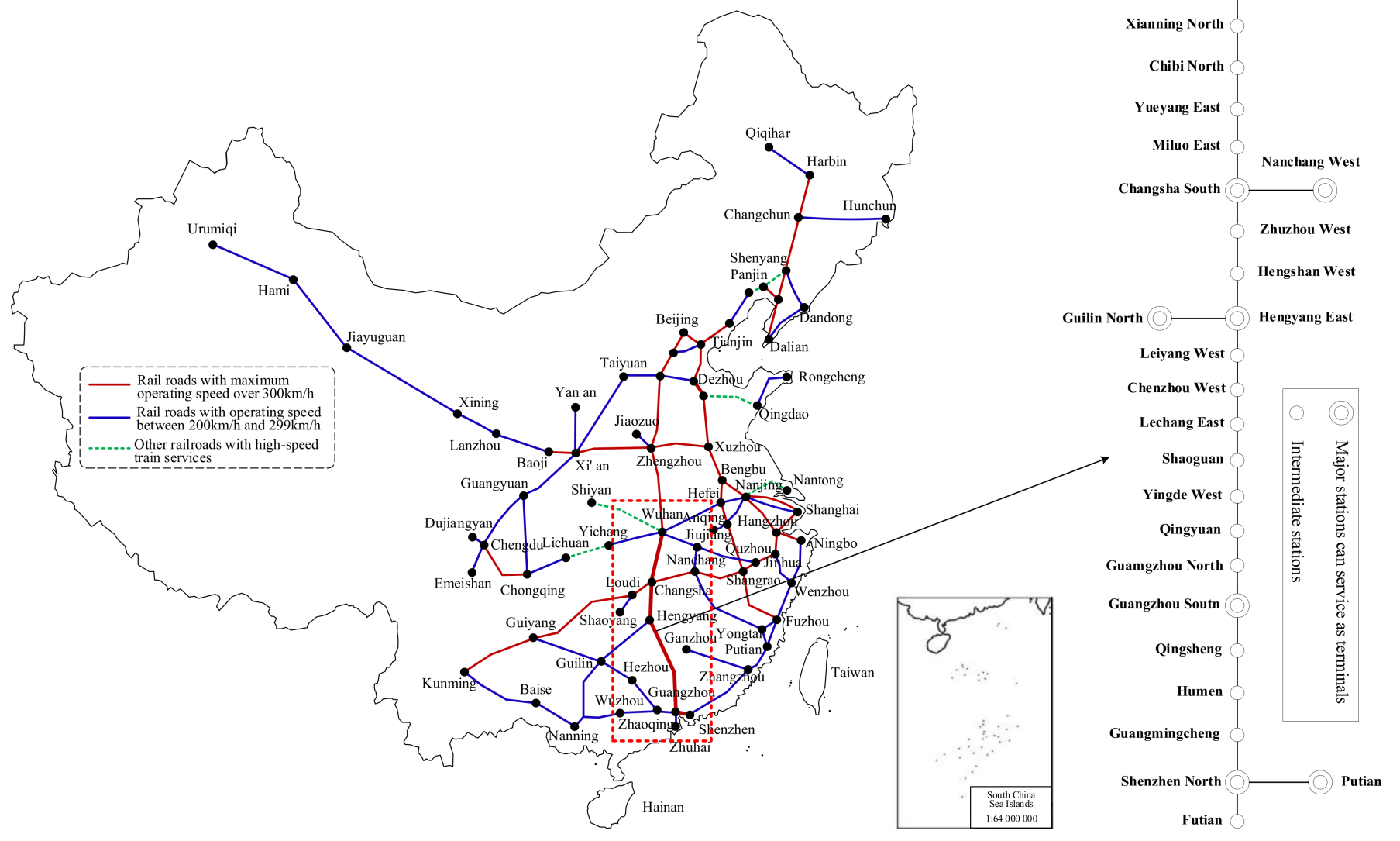

Figure 6. Wuhan-Guangzhou high-speed railway.

Table 2 lists some train schedule information. Fourteen high-speed trains are operated by the China Railway Wuhan Bureau Group Co. Ltd. and 61 high-speed trains are operated by China Railway Guangzhou Bureau Group Co. Ltd.; both companies are the crew depots. Each railway company independently formulates crew scheduling based on their respective train conditions. Table 3 is the original crew scheduling. 
Table 2. Timetable.

\begin{tabular}{|c|c|c|c|c|c|c|}
\hline $\begin{array}{l}\text { Train } \\
\text { ID }\end{array}$ & $\begin{array}{c}\text { Departure } \\
\text { Station }\end{array}$ & $\begin{array}{l}\text { Arrival } \\
\text { Station }\end{array}$ & $\begin{array}{c}\text { Departure } \\
\text { Time }\end{array}$ & $\begin{array}{c}\text { Arrival } \\
\text { Time }\end{array}$ & Train Types & Duration \\
\hline G1003 & Wuhan & Guangzhou South & 07:55 & $12: 01$ & $1^{1}$ & 04:06 \\
\hline G1005 & Wuhan & Guangzhou South & 08:12 & $12: 24$ & $2^{2}$ & $04: 12$ \\
\hline G1007 & Wuhan & Guangzhou South & 09:30 & $13: 37$ & 2 & 04:07 \\
\hline G1013 & Wuhan & Shenzhen North & $12: 07$ & $16: 26$ & 1 & 04:19 \\
\hline G1015 & Wuhan & Guangzhou South & $13: 45$ & $18: 16$ & 2 & 04:31 \\
\hline G1017 & Wuhan & Guangzhou South & $14: 39$ & $18: 51$ & 2 & $04: 12$ \\
\hline G1019 & Wuhan & Guangzhou South & $15: 45$ & $20: 00$ & 2 & $04: 15$ \\
\hline G1021 & Wuhan & Guangzhou South & $16: 58$ & $21: 22$ & 1 & $04: 24$ \\
\hline G1101 & Wuhan & Guangzhou South & $06: 45$ & $11: 11$ & 1 & $04: 26$ \\
\hline G1103 & Wuhan & Guangzhou South & $06: 53$ & $11: 21$ & 1 & $04: 28$ \\
\hline G1105 & Wuhan & Guangzhou South & 07:37 & $11: 31$ & 1 & 03:54 \\
\hline G1107 & Wuhan & Guangzhou South & $08: 26$ & 13:09 & 2 & $04: 43$ \\
\hline G1117 & Wuhan & Guangzhou South & $11: 45$ & $16: 06$ & 1 & $04: 21$ \\
\hline G1123 & Wuhan & Guangzhou South & $13: 58$ & $18: 23$ & 1 & $04: 25$ \\
\hline G1125 & Wuhan & Guangzhou South & $15: 07$ & 19:03 & 1 & 03:56 \\
\hline G1127 & Wuhan & Guangzhou South & $15: 23$ & $19: 34$ & 1 & 04:11 \\
\hline$\vdots$ & $\vdots$ & $\vdots$ & $\vdots$ & $\vdots$ & $\vdots$ & $\vdots$ \\
\hline G1129 & Wuhan & Guangzhou South & $15: 50$ & $19: 47$ & 1 & 03:57 \\
\hline
\end{tabular}

${ }^{1}$ Train with 8-carriages that needs one crew unit; ${ }^{2}$ Train with 16-carriages that needs two crew units.

Table 3. Original train conductors crew scheduling.

\begin{tabular}{|c|c|c|c|c|}
\hline Operators & ID & Duty & Form & $\begin{array}{l}\text { Total Number of } \\
\text { Crew Units }\end{array}$ \\
\hline \multirow{28}{*}{$\begin{array}{c}\text { Wuhan Bureau Group } \\
\text { Co. Ltd. }\end{array}$} & 1 & G1003-G1012 ${ }^{1}$ & $A^{3}$ & \multirow{8}{*}{12} \\
\hline & 2 & G1005 & $\mathrm{A}-\mathrm{A}^{4}$ & \\
\hline & 3 & G1008-G1019 & $\mathrm{A}-\mathrm{A}$ & \\
\hline & 4 & $\overline{\text { G1101-G1116 }}$ & A & \\
\hline & 5 & G1103-G1140 & $\mathrm{A}$ & \\
\hline & 6 & G1105-G1120-G1133 & $\mathrm{A}$ & \\
\hline & 7 & G1107-G1124 & A-A & \\
\hline & 8 & G1007-G1018 & A-A & \\
\hline & 9 & G1002-G1013-G6024 ${ }^{2}$ & $\mathrm{~A}$ & \multirow{20}{*}{26} \\
\hline & 10 & G1004-G1015 & A-A & \\
\hline & 11 & G1006-G1017 & A-A & \\
\hline & 12 & G6013-G1010-G1021 & A & \\
\hline & 13 & $\overline{\mathrm{G} 1102-G 1117-G 1134}$ & A & \\
\hline & 14 & G1108-G1123 & $\mathrm{A}$ & \\
\hline & 15 & G6101-G1110-G1125-6116 & A & \\
\hline & 16 & G1112-G1127-G6118 & A & \\
\hline & 17 & G6105-G1114-G1129-G6120 & $\mathrm{A}$ & \\
\hline & 18 & G1122-G1135 & $\mathrm{A}$ & \\
\hline & 19 & G1014 & A-A & \\
\hline & 20 & G6011-G6016-G6001G6026 & A & \\
\hline & 21 & $\overline{\mathrm{G} 6132-G 6131-G 6110-G 6119}$ & $\mathrm{~A}$ & \\
\hline & 22 & G6015-G6018-G6031 & A-A & \\
\hline & 23 & G6029-G6034-G6033 & A & \\
\hline & 24 & G6017-G6020-G6117-G6122 & A & \\
\hline & 25 & G6021-G6022-G6027 & A-A & \\
\hline & 26 & G6012-G6019-G6002-G6025 & A-A & \\
\hline & 27 & G6111-G6112 & $\mathrm{A}$ & \\
\hline & 28 & G6103-G6030 & A & \\
\hline
\end{tabular}

${ }^{1}$ The train operated by Wuhan Bureau Group Co. Ltd.; ${ }^{2}$ The train operated by Guangzhou Bureau Group Co Ltd.; ${ }^{3}$ Each train in the duty needs one crew unit; ${ }^{4}$ Each train in the duty needs two crew units. 
The time needed for the crew unit to perform preparatory activities before each duty and shift handover after each duty are both two hours. The standard transit time between trips is $20 \mathrm{~min}$. The maximum allowed work time for a crew unit is $12 \mathrm{~h}$.

The case is solved through the improved GA using Python 3.6 on a PC with a Intel (R) Core (TM) i7-6700 CPU 3.40 and 8.0 GB of RAM.

\subsection{Parameter Tune and Performance Analysis}

First, the experiment is repeated 50 times with different crossover rates (pc) and mutation rates (pm), setting the population size (pop size) of each generation to 100 [55]. Figure 7 shows the distributions of the objective value with different combinations of $\mathrm{pc}$ and pm, and the optimal objective values are listed in Table 4 . From Table 4, we can see that the optimal objective value was obtained with $\mathrm{pc}=0.7$ and $\mathrm{pm}=0.04$. The objective value no longer decreased with the increase in $\mathrm{pc}$ and $\mathrm{pm}$, indicating that the algorithm has reached convergence. In addition, the optimal value was found within fifty iterations.

Table 4. The optimal objective value of experiments with different combinations of pc and pm.

\begin{tabular}{cccccccc}
\hline ID & $\mathbf{p c}$ & $\mathbf{p m}$ & Objective Value & ID & pc & pm & Objective Value \\
\hline 1 & 0.3 & 0.01 & 13,800 & 14 & 0.5 & 0.04 & 13,571 \\
2 & 0.3 & 0.02 & 13,764 & 15 & 0.5 & 0.05 & 13,560 \\
3 & 0.3 & 0.03 & 13,700 & 16 & 0.6 & 0.01 & 13,640 \\
4 & 0.3 & 0.04 & 13,680 & 17 & 0.6 & 0.02 & 13,600 \\
5 & 0.3 & 0.05 & 13,674 & 18 & 0.6 & 0.03 & 13,574 \\
6 & 0.4 & 0.01 & 13,750 & 19 & 0.6 & 0.04 & 13,472 \\
7 & 0.4 & 0.02 & 13,700 & 20 & 0.6 & 0.05 & 13,472 \\
8 & 0.4 & 0.03 & 13,680 & 21 & 0.7 & 0.01 & 13,600 \\
9 & 0.4 & 0.04 & 13,605 & 22 & 0.7 & 0.02 & 13,580 \\
10 & 0.4 & 0.05 & 13,600 & 23 & 0.7 & 0.03 & 13,564 \\
11 & 0.5 & 0.01 & 13,680 & 24 & 0.7 & 0.04 & 13,472 \\
12 & 0.5 & 0.02 & 13,650 & 25 & 0.7 & 0.05 & - \\
13 & 0.5 & 0.03 & 13,635 & - & - & & - \\
\hline
\end{tabular}

Based on the above results, we used variable mutation rates to improve the solution quality. The specific parameter setting of the improved GA are shown in Table 5. The results are shown in Figure 8. We can conclude that: (1) compared with the fixed $p m$, the variable pm can avoid premature convergence of GA; and (2) the objective value is optimized by $1.65 \%$ with $p m=0.05(\mathrm{~N} \leq 30)$ and $p m=0.06(\mathrm{~N}>30)$.

Table 5. Mutation rate experimental parameters.

\begin{tabular}{cccccc}
\hline \multirow{2}{*}{ Experiment ID } & Pop Size & $\mathbf{N}$ & pc & \multicolumn{2}{c}{ pm } \\
\cline { 5 - 6 } & & & & $\mathbf{N} \leq 30$ & $\mathbf{N} \geq 30$ \\
\hline 1 & 100 & 60 & 0.6 & 0.04 & 0.04 \\
3 & 100 & 60 & 0.6 & 0.04 & 0.05 \\
4 & 100 & 60 & 0.6 & 0.05 & 0.05 \\
5 & 100 & 60 & 0.6 & 0.05 & 0.06 \\
6 & 100 & 60 & 0.6 & 0.06 & 0.06 \\
\end{tabular}




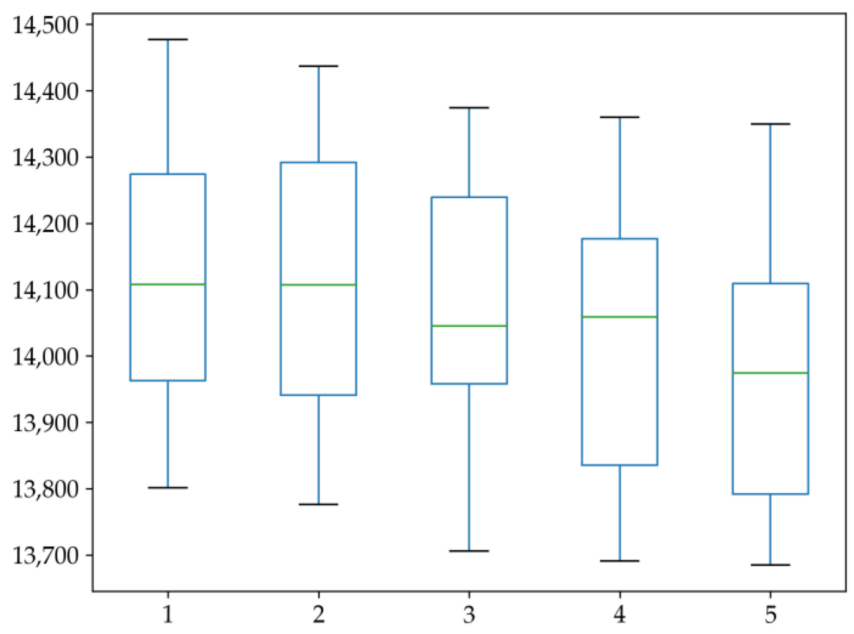

(a) Distributions of objective value when $\mathrm{pc}=0.3$, pm changes from 0.01 to 0.05

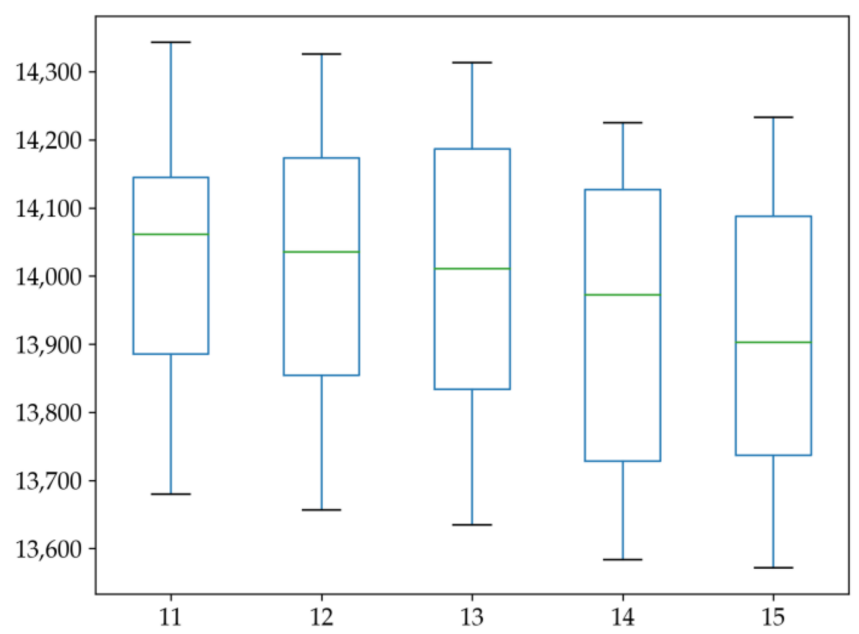

(c) Distributions of objective value when $\mathrm{pc}=0.5$, pm changes from 0.01 to 0.05

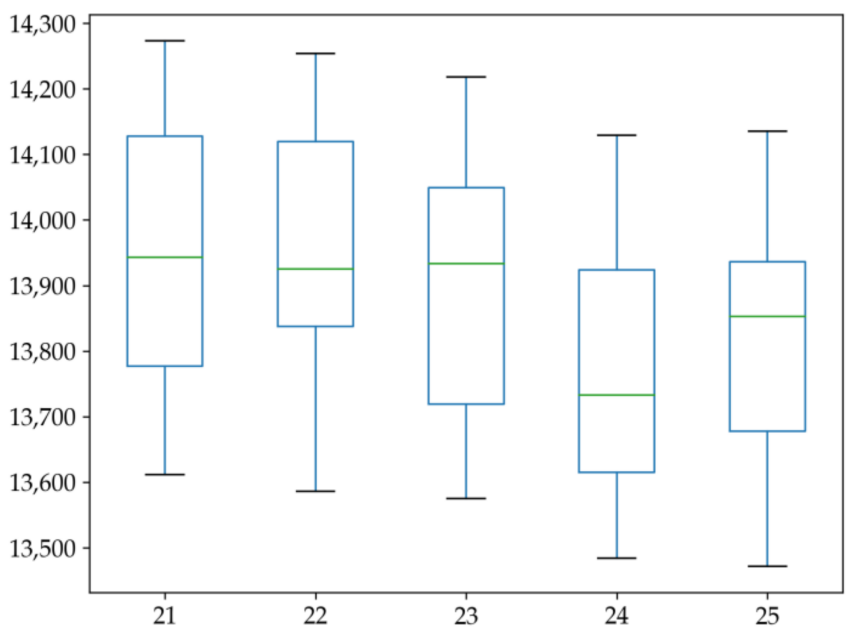

(e) Distributions of objective value when $\mathrm{pc}=0.7$, pm changes from 0.01 to 0.05

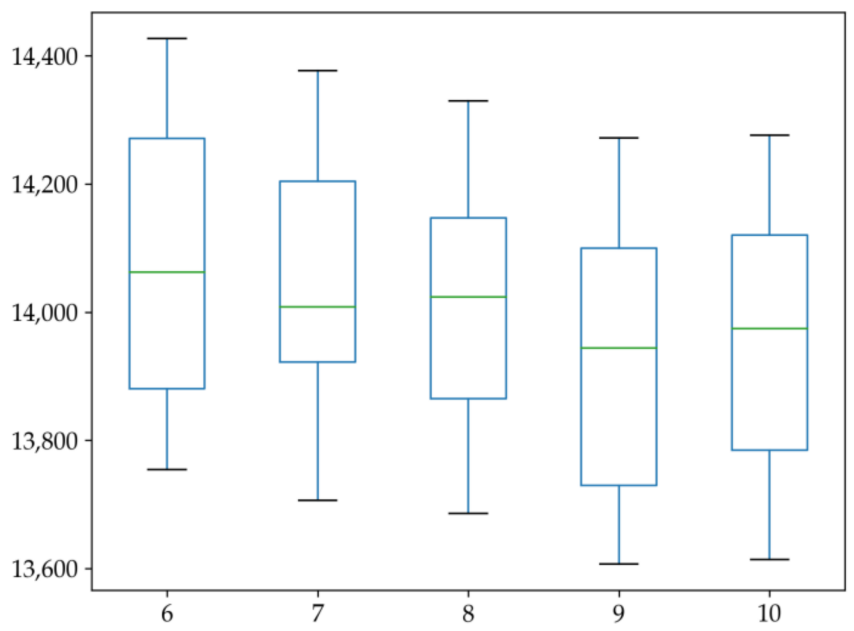

(b) Distributions of objective value when $\mathrm{pc}=0.4$, pm changes from 0.01 to 0.05

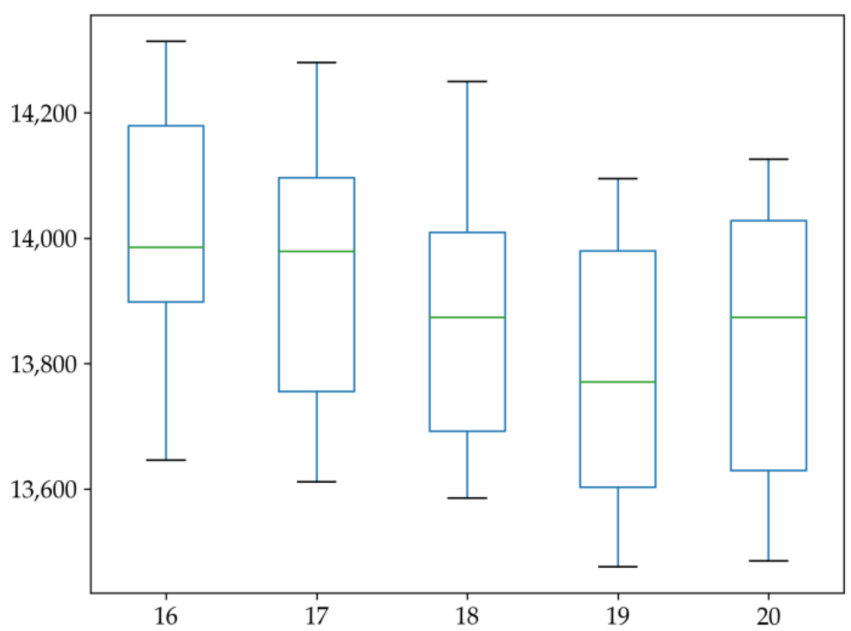

(d) Distributions of objective value when $\mathrm{pc}=0.6$, pm changes from 0.01 to 0.05

Figure 7. Distributions of objective value with different combinations of pc and pm. 


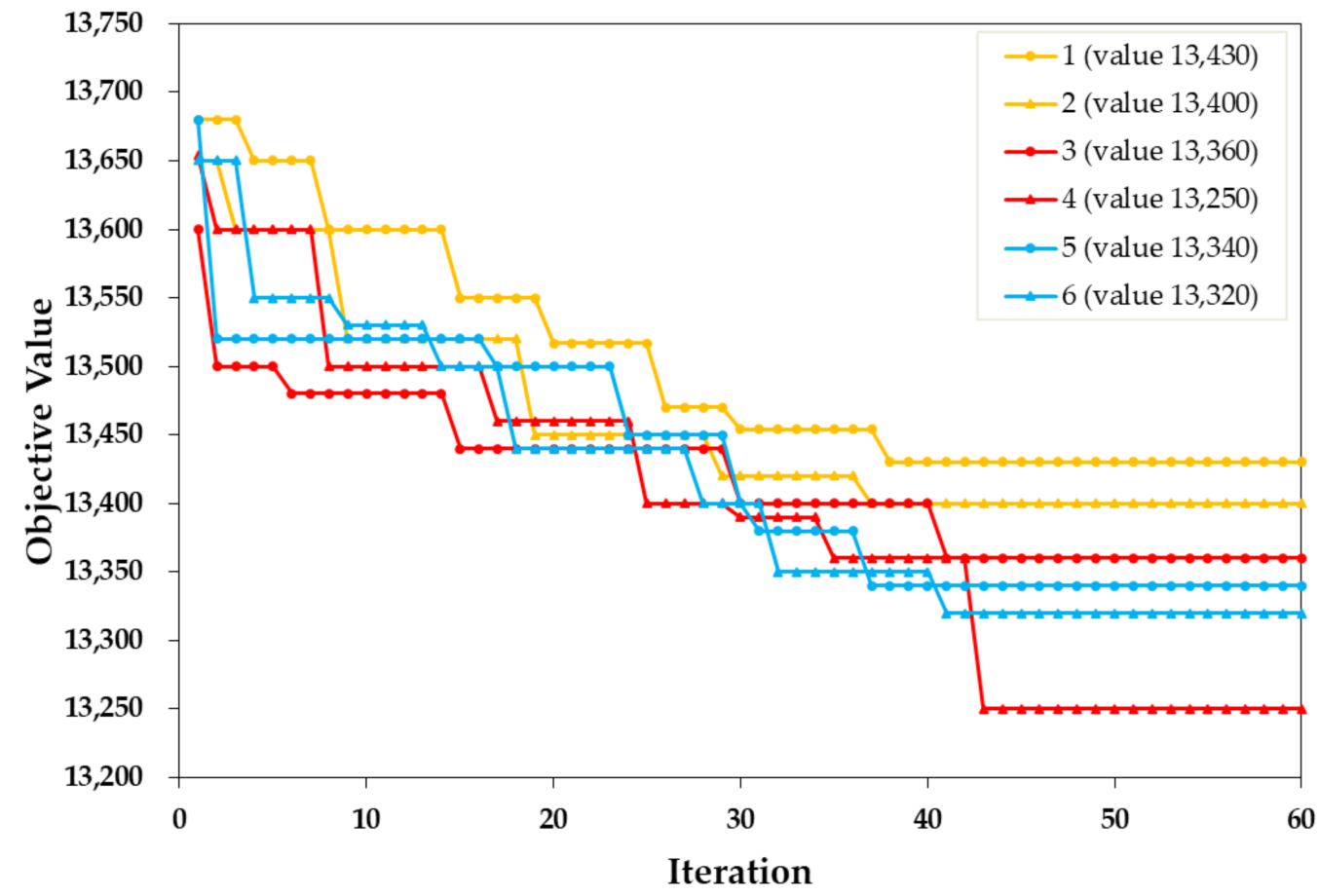

Figure 8. Summary of the experimental results on the variable mutation rate. Six groups of experiments were selected and convergence results were obtained after 50 iterations. Experiment 4 had the best result with a value of 13,250

Next, we compared the improved GA with the classical GA, PSO, and TS under the same maximum iteration. Fifty experiments were conducted. As shown in Table 6, we can conclude the following. (1) The classical PSO costs the least time, but finds the worst solution. The objective values obtained by classical GA is better than classical PSO and TS, but needs more time. Overall, the performance of the classical TS is between the classical GA and classical PSO. This may be because PSO is better at dealing with continuous optimization problems, and TS depends on the neighborhood search rules. As for GA, it needs more time for global search. (2) The improved GA took $58 \mathrm{~s}$ on average to find the optimal objective value, and the objective value was reduced by $4.47 \%$ compared with the classical GA. Compared with the classical GA, classical PSO, and classical TS, although the improved GA needed more time to find the optimal solution, it is acceptable, and the objective value was optimized by more than $4.47 \%$.

Table 6. Comparison results of classical GA, classical PSO, classical TS, and improved GA.

\begin{tabular}{cccc}
\hline Algorithm & Best Objective Value & $\begin{array}{c}\text { Average Feasible } \\
\text { Solution Rate }\end{array}$ & $\begin{array}{c}\text { Average Running } \\
\text { Time }\end{array}$ \\
\hline Classical GA & 13,871 & $83 \%$ & $41 \mathrm{~s}$ \\
Classical PSO & 14,515 & $74 \%$ & $24 \mathrm{~s}$ \\
Classical TS & 14,017 & $81 \%$ & $31 \mathrm{~s}$ \\
Improved GA & 13,250 & $100 \%$ & $58 \mathrm{~s}$ \\
\hline
\end{tabular}

The results show that the improved measures proposed in this paper can effectively remedy the shortcomings of the classical GA and improve spatial searchability. A better solution was obtained with finite computing time.

\subsection{Results, Discussion, and Analysis}

The optimal crew scheduling plan is shown in Table 7. Without the restriction of the crew depot, the trips of the Wuhan Bureau Group Co. Ltd. can be connected with the trips 
of the Guangzhou Bureau Group Co. Ltd. and form a duty together. However, this is not allowed in original crew scheduling. The G1004 of Guangzhou Bureau Group Co. Ltd. can only connect with the G1015 in the original crew scheduling (Table 3), and the duration of the duty is $520 \mathrm{~min}$, which is $200 \mathrm{~min}$ less than the required work time. In the improved crew scheduling plan, the G1004, G1015, and G6116 of the Guangzhou Bureau Group Co. can be connected with the G1140 of Wuhan Bureau Group Co. Ltd., and the duration of the duty was up to $645 \mathrm{~min}$, increasing the duration of the duty by $25.96 \%$ compared with the original crew scheduling plan within the maximum allowed work time. The utilization of the crew units working time was obviously improved.

Table 7. The optimized crew scheduling based on multi-crew depots.

\begin{tabular}{|c|c|c|c|c|}
\hline Operators & ID & Duty & Form & $\begin{array}{l}\text { Total Number of } \\
\text { Crew Units }\end{array}$ \\
\hline \multirow{6}{*}{$\begin{array}{c}\text { Wuhan Bureau Group } \\
\text { Co. Ltd. }\end{array}$} & 1 & G1101-G1116-G1021 & $\mathrm{A}$ & \multirow{7}{*}{10} \\
\hline & 2 & 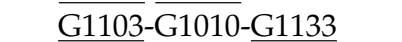 & A & \\
\hline & 3 & G1105-G1120-G1135 & A & \\
\hline & 4 & $\mathrm{G} 1003-\mathrm{G} 1122$ & $\mathrm{~A}$ & \\
\hline & 5 & G1005-G1124 & A-A & \\
\hline & 6 & $\overline{\mathrm{G} 1107}-\overline{\mathrm{G} 1018}$ & A-A & \\
\hline \multirow{23}{*}{$\begin{array}{l}\text { Guangzhou Bureau } \\
\text { Group Co. Ltd. }\end{array}$} & 7 & G1007-G1014 & A-A & \\
\hline & 8 & G1102-G1117-G1134 & A & \multirow{22}{*}{25} \\
\hline & 9 & G6132-G6131-G6110-G6119 & A & \\
\hline & 10 & G6011-G6016-G6001-G6030 & A & \\
\hline & 11 & G6101-G1110-G1125 & A & \\
\hline & 12 & G6013-G1112-G1127 & A & \\
\hline & 13 & G6103-G1012 & A & \\
\hline & 14 & G1002-G1013-G6024 & A & \\
\hline & 15 & G6105-G1008-G1019 & $\mathrm{A}$ & \\
\hline & 16 & G6012-G6019-G6022-G6027 & A-A & \\
\hline & 17 & G6015-G6034-G6033 & A & \\
\hline & 18 & G6015-G6018-G6031-G6026 & $\mathrm{A}$ & \\
\hline & 19 & G6029-G6018-G6031 & A & \\
\hline & 20 & G1004-G1015-G1140-G6116 & A-A & \\
\hline & 21 & G1108-G1123-G6120 & A & \\
\hline & 22 & G6017-G6020-G6117-G6122 & $\mathrm{A}$ & \\
\hline & 23 & G1006-1017-G6118 & A & \\
\hline & 24 & G1006-1017 & $\mathrm{A}$ & \\
\hline & 25 & G6024-G6110 & A & \\
\hline & 26 & G6021-6002-6025 & A-A & \\
\hline & 27 & G1008-G1019 & A & \\
\hline & 28 & G1114-G1129 & A & \\
\hline & 29 & G6111-G6112 & $\mathrm{A}$ & \\
\hline
\end{tabular}

Furthermore, this paper solves the crew scheduling problem with different train types by disassembling the train with 16-carriages into the standard train (a trip need a crew unit) with 8-carriages, as shown in Figure 9. Thus, the crew scheduling can be more flexible, and more train types can also be handled in this way.

The left of Figure 9 is a part of the original crew scheduling plan, where G1006 and G1007 are both trains with 16-carriages and form duty 11 together, which need two crew units. The right of Figure 9 is a part of the modified crew scheduling plan, where G1006 and G1017 are considered as two trains with 8-carriages, respectively. Each trip can connect with any other trip, satisfying the constraints to form a duty. Therefore, duty 11 is split into duty 23 and duty 24. Each duty is the content of one crew unit. It is worth noting that a new trip of G6118 was added on duty 23. Because the proposed method can solve the connection of different train types, there was an increase in the crew unit working time not exceeding the maximum allowed work time. 


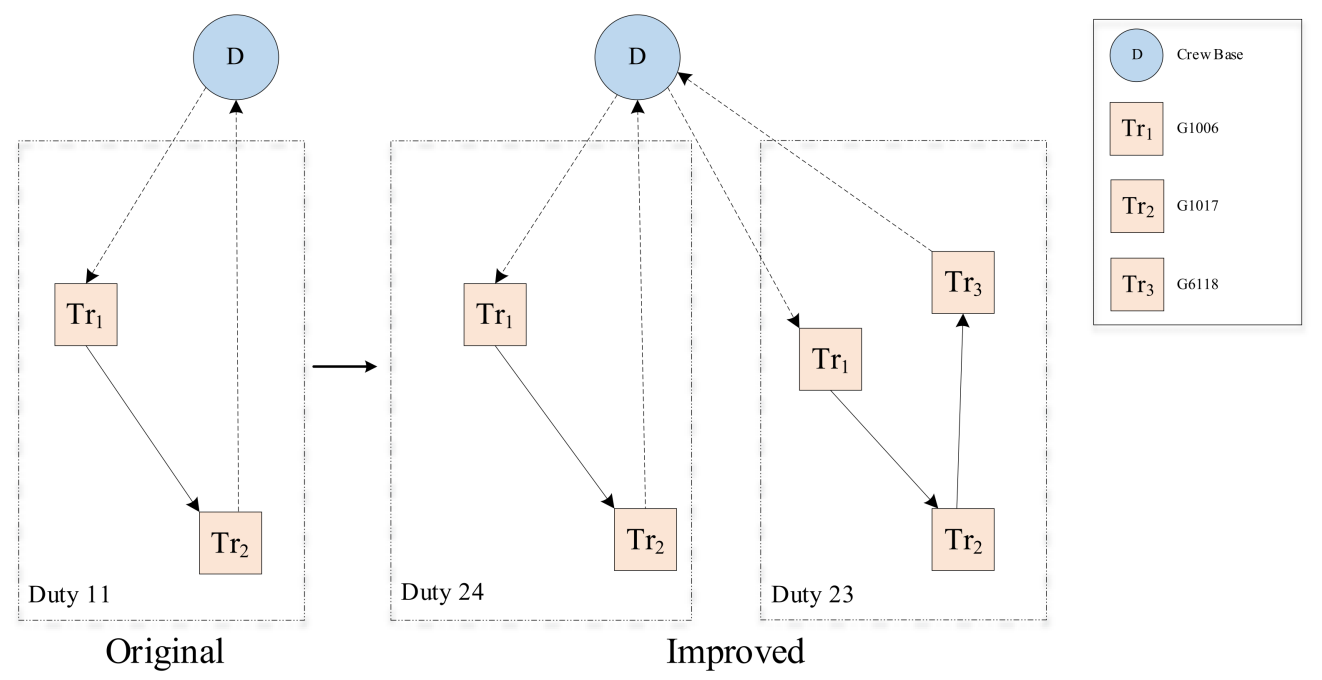

Figure 9. The trip connection between different train types. The left is a part of the original crew scheduling and the right is a part of the improved crew scheduling.

The comparison results between the optimized crew scheduling plan and the original one are shown in Table 8. From Table 8, we can draw the following conclusions: (1) $35 \mathrm{crew}$ units were required to carry out the operation of 75 trips, which reduced three crew units compared with the original crew scheduling plan; (2) The average transit time between trips in duty was $54.38 \mathrm{~min}$ in this paper, which was $22.76 \%$ lower than the original crew scheduling plan; (3) The average duty time was $640.67 \mathrm{~min}$, which was $7.75 \%$ shorter than the original crew scheduling plan; (4) The utilization of crew unit work was $87.34 \%$ in the optimized crew scheduling plan, which was $6.20 \%$ higher than the original scheme. In summary, the method proposed in this paper completed the same task with fewer crew units, and the crew's working time was effectively utilized, which is conducive to people's sustainable development.

Table 8. Results between original and improved train conductors crew scheduling.

\begin{tabular}{ccccc}
\hline $\begin{array}{c}\text { Crew } \\
\text { Scheduling }\end{array}$ & $\begin{array}{c}\text { Number of } \\
\text { Crew Units }\end{array}$ & $\begin{array}{c}\text { Average Transit } \\
\text { Time (min) }\end{array}$ & $\begin{array}{c}\text { Average Duty } \\
\text { Time (min) }\end{array}$ & $\begin{array}{c}\text { Average Duty } \\
\text { Efficiency (\%) }\end{array}$ \\
\hline original & 38 & 70.41 & 694.50 & $80.14 \%$ \\
improved & 35 & 54.38 & 640.67 & $86.34 \%$ \\
\hline
\end{tabular}

\section{Conclusions}

After the analysis of the differences in the operational policies between the drivers and conductors, a model on the railway crew scheduling problem was proposed. The proposed method breaks the restriction of the crew depot from the perspective of the sustainable development of mankind, and allows the crew unit to be on duty for all trips on the premise of meeting the work requirements. Therefore, the working time of the crew unit can be effectively utilized and sustainable. Furthermore, the proposed method can be used to solve the crew scheduling problem with more complex train types.

An improved GA was proposed and used to solve the problem. In the improved GA, the repair mechanism of infeasible genes transferred the infeasible solution to a feasible solution, improving the search space of solutions and the quality of the solutions. By using the improved GA, the optimal solution can be obtained within an acceptable time cost.

The proposed algorithm was applied to the Wuhan-Guangzhou high-speed railway, and the results showed that the modified crew scheduling plan reduced three crew units and increased the average utilization of crew unit working time by $6.20 \%$. Besides, compared with the classical GA, the classical PSO and the classical TS, the improved GA effectively alleviated premature convergence and reduced the objective value of the solution by about 
more than $4.47 \%$. All of the results verified the applicability and validity of the model and the algorithm proposed, which will significantly improve the service of the high-speed railway.

In future work, the cooperation mode between multiple crew depots will be studied in detail, for example, the cooperation mode on crew bases of the same or the different railway companies, the distribution problem of trips of the different crew bases, and the cost allocation problem. Besides, more powerful models and effective solution algorithms will be developed. Furthermore, research on real-time scheduling could lead to higher customer satisfaction in a fast-moving world with information available instantly, so the robust crew schedules could also be our focus for future studies.

Author Contributions: Conceptualization, C.Z. and J.C.; Methodology, C.Z., Z.C. and X.Z.; Software, C.Z. and Z.C.; Validation, C.Z., J.C. and X.Z.; Formal analysis, C.Z., X.Z. and Z.C.; Investigation, C.Z. and J.C.; Resources, C.Z.; Data curation, J.C.; Writing-original draft preparation, C.Z., J.C. and X.Z.; Writing-review and editing, C.Z., J.C. and Z.C.; Visualization, C.Z. and X.Z.; Supervision, C.Z. and X. Z.; Project administration, C.Z. and J.C.; Funding acquisition, X.Z. and J.C. All authors have read and agreed to the published version of the manuscript.

Funding: This paper is mainly supported by the National Natural Science Foundation of China (Grant No. U1734204).

Data Availability Statement: The data involved in this article is the industry's internal data provided by the project (Grant No. U1734204).

Acknowledgments: Many thanks to Zhimei Wang, Tan Liu, Zhou Zhou, Ning Zeng and Han Zheng for their help and support on this paper.

Conflicts of Interest: The authors declare no conflict of interest.

\section{References}

1. Arabeyre, J.P.; Fearnley, J.; Steiger, F.C.; Teather, W. The Airline Crew Scheduling Problem: A Survey. Transp. Sci. 1969, 3, 140-163. [CrossRef]

2. Carraresi, P.; Gallo, G. Network models for vehicle and crew scheduling. Eur. J. Oper. Res. 1984, 16, 139-151. [CrossRef]

3. Elms, J.M. The use of computers in bus and crew Scheduling by london buses and its predecessors: A user's view. from the book computer-aided transit scheduling. In Proceedings of the Fourth International Workshop on Computer-Aided Scheduling of Public Transport, Hamburg, Germany, 28-31 July 1987; pp. 262-271.

4. Sylvie, L.; Michel, M.; Edouard, O. A new approach for crew pairing problems by column generation with an application to air transportation. Eur. J. Oper. Res. 1988, 35, 45-58.

5. Gershkoff, I. Optimizing Flight Crew Schedules. Interfaces 1989, 19, 29-43. [CrossRef]

6. Smith, B.M.; Wren, A. A bus crew scheduling system using a set covering formulation. Transp. Res. Part A: Gen. 1988, 22, 97-108. [CrossRef]

7. DesRochers, M.; Soumis, F. A Column Generation Approach to the Urban Transit Crew Scheduling Problem. Transp. Sci. 1989, 23, 1-13. [CrossRef]

8. Lourenco, H.R.; Paixao, J.P.; Portugal, R. Multiobjective Metaheuristics for the Bus Driver Scheduling Problem. Transp. Sci. 2001, 35, 331-343. [CrossRef]

9. Deveci, M.; Demirel, N. Çetin A survey of the literature on airline crew scheduling. Eng. Appl. Artif. Intell. 2018, 74, 54-69. [CrossRef]

10. Kohl, N.; Karisch, S.E. Airline Crew Rostering: Problem Types, Modeling, and Optimization. Ann. Oper. Res. 2004, 127, $223-257$. [CrossRef]

11. Kasirzadeh, A.; Saddoune, M.; Soumis, F. Airline crew scheduling: Models, algorithms, and data sets. EURO J. Transp. Logist. 2017, 6, 111-137. [CrossRef]

12. Doi, T.; Nishi, T.; Voß, S. Two-level decomposition-based matheuristic for airline crew rostering problems with fair working time. Eur. J. Oper. Res. 2018, 267, 428-438. [CrossRef]

13. Şafak, Özge; Çavuş, Özlem; Akturk, S. Multi-stage airline scheduling problem with stochastic passenger demand and non-cruise times. Transp. Res. Part B: Methodol. 2018, 114, 39-67. [CrossRef]

14. Wen, X.; Sun, X.; Sun, Y.; Yue, X. Airline crew scheduling: Models and algorithms. Transp. Res. Part E: Logist. Transp. Rev. 2021, 149, 102304. [CrossRef]

15. Caprara, A.; Toth, P.; Vigo, D.; Fischetti, M. Modeling and Solving the Crew Rostering Problem. Oper. Res. 1998, 46, 820-830. [CrossRef] 
16. Morgado, E.M.; Martins, J.P. Scheduling and managing crew in the Portuguese railways. Expert Syst. Appl. 1992, 5, 301-321. [CrossRef]

17. Heil, J.; Hoffmann, K.; Buscher, U. Railway crew scheduling: Models, methods and applications. Eur. J. Oper. Res. 2020, 283, 405-425. [CrossRef]

18. Caprara, A.; Fischetti, M.; Toth, P.; Vigo, D.; Guida, P.L. Algorithms for railway crew management. Math. Program. 1997, 79, 125-141. [CrossRef]

19. Mingozzi, A.; Boschetti, M.A.; Ricciardelli, S.; Bianco, L. A Set Partitioning Approach to the Crew Scheduling Problem. Oper. Res. 1999, 47, 873-888. [CrossRef]

20. Hanczar, P.; Zandi, A. A novel model and solution algorithm to improve crew scheduling in railway transportation: A real world case study. Comput. Ind. Eng. 2021, 154, 107132. [CrossRef]

21. Kuznetsov, N.; Minashina, I.; Ryabykh, N.; Zakharova, E.; Pashchenko, F. Design and Comparison of Freight Scheduling Algorithms for Intelligent Control Systems. Procedia Comput. Sci. 2016, 98, 56-63. [CrossRef]

22. Vaidyanathan, B.; Jha, K.C.; Ahuja, R.K. Multicommodity network flow approach to the railroad crew-scheduling problem. IBM J. Res. Dev. 2007, 51, 325-344. [CrossRef]

23. Caprara, A. Timetabling and assignment problems in railway planning and integer multicommodity flow. Networks 2015, 66, 1-10. [CrossRef]

24. Caprara, A.; Kroon, L.; Monaci, M.; Peeters, M.; Toth, P. Passenger Railway Optimization. Handb. Oper. Res. Manag. Sci. 2007, 14, 129-187.

25. Cadarso, L.; Marín, A. Integration of timetable planning and rolling stock in rapid transit networks. Ann. Oper. Res. 2011, 199, 113-135. [CrossRef]

26. Meng, L.; Corman, F.; Zhou, X.; Tang, T. Special issue on Integrated optimization models and algorithms in rail planning and control. Transp. Res. Part C: Emerg. Technol. 2018, 88, 87-90. [CrossRef]

27. Bach, L.; Dollevoet, T.; Huisman, D. Integrating Timetabling and Crew Scheduling at a Freight Railway Operator. Transp. Sci. 2016, 50, 878-891. [CrossRef]

28. Zhou, J.; Xu, X.; Long, J.; Ding, J. Integrated optimization approach to metro crew scheduling and rostering. Transp. Res. Part C: Emerg. Technol.. [CrossRef]

29. Huisman, D. A column generation approach for the rail crew re-scheduling problem. Eur. J. Oper. Res. 2007, 180, 163-173. [CrossRef]

30. Veelenturf, L.P.; Potthoff, D.; Huisman, D.; Kroon, L.G. Railway crew rescheduling with retiming. Transp. Res. Part C: Emerg. Technol. 2012, 20, 95-110. [CrossRef]

31. Lai, D.S.W.; Leung, J.M.Y. Real-time rescheduling and disruption management for public transit. Transp. B: Transp. Dyn. 2017, 6, 17-33. [CrossRef]

32. Yaghini, M.; Karimi, M.; Rahbar, M. A set covering approach for multi-depot train driver scheduling. J. Comb. Optim. 2015, 29, 636-654. [CrossRef]

33. Derigs, U.; Malcherek, D.; Schäfer, S. Supporting strategic crew management at passenger railways-model, method and system Public Transp. 2010, 2, 307-334. [CrossRef]

34. Hoffmann, K.; Buscher, U. Valid inequalities for the arc flow formulation of the railway crew scheduling problem with attendance rates. Comput. Ind. Eng. 2019, 127, 1143-1152. [CrossRef]

35. Muroi, Y.; Nishi, T.; Inuiguchi, M. Improvement of Column Generation Method for Railway Crew Scheduling Problems. IEEJ Trans. Electron. Inf. Syst. 2010, 130, 275-283. [CrossRef]

36. Shen, Y.; Chen, S.; Su, X. Rail Crew Scheduling Based on a Pooling Mode for High Speed Passenger Lines. In Proceedings of the 2010 International Conference on Logistics Engineering and Intelligent Transportation Systems, Wuhan, China, 26-28 November 2010; pp. 1-4.

37. Veelenturf, L.P.; Potthoff, D.; Huisman, D.; Kroon, L.G.; Maróti, G.; Wagelmans, A.P. A Quasi-Robust Optimization Approach for Crew Rescheduling. Transp. Sci. 2016, 50, 204-215. [CrossRef]

38. Jütte, S.; Müller, D.; Thonemann, U.W. Optimizing railway crew schedules with fairness preferences. J. Sched. 2017, 20, 43-55. [CrossRef]

39. Chu, H.D., Gelman. Solving large scale crew scheduling problems. Eur. J. Oper. Res. 1997, 97, 260-268. [CrossRef]

40. Chen, S.; Shen, Y.; Su, X.; Chen, H. A Crew Scheduling with Chinese Meal Break Rules. J. Transp. Syst. Eng. Inf. Technol. 2013, 13, 90-95. [CrossRef]

41. Shen, Y. An estimation of distribution algorithm for public transport driver scheduling. Oper. Res. 2017, 28, 245-262. [CrossRef]

42. Pan, H.; Liu, Z.; Yang, L.; Liang, Z.; Wu, Q.; Li, S. A column generation-based approach for integrated vehicle and crew scheduling on a single metro line with the fully automatic operation system by partial supervision. Transp. Res. Part E: Logist. Transp. Rev. 2021, 152, 102406. [CrossRef]

43. Neufeld, J.S.; Scheffler, M.; Tamke, F.; Hoffmann, K.; Buscher, U. An efficient column generation approach for practical railway crew scheduling with attendance rates. Eur. J. Oper. Res. 2021, 293, 1113-1130. [CrossRef]

44. Manuel, F.; Luis, C.; Ángel, M. A hybrid model for crew scheduling in rail rapid transit networks. Transp. Res. Part B: Methodol. $2019,125,248-265$. 
45. Elizondo, R.; Parada, V.; Pradenas, L.; Artigues, C. An evolutionary and constructive approach to a crew scheduling problem in underground passenger transport. J. Heuristics 2009, 16, 575-591. [CrossRef]

46. Kwan, R.S.K. Case studies of successful train crew scheduling optimisation. J. Sched. 2011, 14, 423-434. [CrossRef]

47. Hoffmann, K. A Hybrid Solution Approach for Railway Crew Scheduling Problems with Attendance Rates. In Operations Research Proceedings; Springer International Publishing: Cham, Switzerland, 2017.

48. Fraszczyk, A.; Marinov, M. Sustainable Rail Transport; Springer: Cham, Switzerland, 2018.

49. Balakrishnan, A.; Kuo, A.; Si, X. Real-Time Decision Support for Crew Assignment in Double-Ended Districts for U.S. Freight Railways. Transp. Sci. 2016, 50, 1337-1359. [CrossRef]

50. Holland, H.J. Adaptation in Natural and Artificial Systems: An Introductory Analysis with Applications to Biology, Control, and Artificial Intelligence; The MIT Press: Cambridge, MA, USA, 1992.

51. Reeves, C.R. Modern Heuristic Techniques for Combinatorial Problems; John Wiley \& Sons, Inc.: New York, NY, USA, 1993.

52. Song, C.; Guan, W.; Ma, J.; Liu, T. Improved Genetic Algorithm with Gene Recombination for Bus Crew-Scheduling Problem. Math. Probl. Eng. 2015, 2015, 719409. [CrossRef]

53. Escobar, Z.A.H.; Gallego, R.R.A.; Romero, L.R.A. Using traditional heuristic algo-algorithms on an initial genetic algo- rithms algorithm population applied to the rithm transmission expansion planning problem. Ing. Investig. 2011, 31, 127-423.

54. Abdoun, O.; Abouchabaka, J. A Comparative Study of Adaptive Crossover Operators for Genetic Algorithms to Resolve the Traveling Salesman Problem. arXiv 2012, arXiv:1203.3097.

55. Beasley, J.; Chu, P. A genetic algorithm for the set covering problem. Eur. J. Oper. Res. 1996, 94, 392-404. [CrossRef] 